\title{
Mediação Teatral: ANOtAÇões sobre 0 Projeto Formação de Público
}

\author{
Flávio Desgranges ${ }^{1}$
}

Procurarei tecer aqui um breve relato do Projeto Formação de Público, do qual participei como orientador em 2004, justamente o seu último ano de existência. O projeto era uma iniciativa da Secretaria Municipal de Cultura de São Paulo e fora criado em 2001, sendo extinto, como se tornou usual em nosso país, assim que a nova gestão assumiu a prefeitura, em 2005. Um novo governo, como bem sabemos, faz terra arrasada das conquistas engendradas na gestão anterior. Mas podemos aproveitar espaços de reflexão como este para manter vivas algumas experiências realizadas, evitando em parte - em pequena parte talvez - que os ventos da pretensa novidade continuem a varrer e a transformar em caco a nossa história.

Importa ressaltar que, em cada um dos quatro anos de duração do projeto, os procedimentos artísticos e pedagógicos adotados foram alterados completamente. Estas alterações foram decorrentes de necessidades observadas pelos coordenadores, com o intuito de ampliar e aprimorar as suas ações. O que, não posso deixar de notar, convida a que se faça, em outro momento, um estudo detalhado dos percursos deste projeto, das tantas descobertas e dificuldades encontradas em sua trajetória. A minha opção por abordar a experiência de 2004 se dá especialmente porque não participei das outras versões do projeto, e não poderia apresentá-las com conhecimento de causa. Neste ano o Formação contou também com a orientação de Luiz Fernando Ramos, de Silvia Fernandes e de Flávio Aguiar, e com a curadoria de Gianni Ratto. Além da atuação de sete coordenadores e de quarenta e dois monitores.

Esclareço ainda que selecionei alguns aspectos da nossa atuação para que possamos pensar a partir destes recortes, já que a iniciativa era bastante grandiosa em suas dimensões, e talvez também em suas pretensões. Em 2004,

1Professor do Departamento de Artes Cênicas da USP, autor dos seguintes livros: "A Pedagogia do Espectador", Ed. Hucitec, 2003;

"Pedagogia do Teatro: provocação e dialogismo", Ed. Hucitec, 2006. 
participaram da ação um total de 305 escolas municipais, com um público estimado de 257.000 alunos. Eram 11 grupos teatrais que circulavam com seus espetáculos, apresentados durante o ano letivo, às terças e quintas-feiras às 8 horas da noite, para jovens e adultos do ensino médio. Nos finais de semana, uma vez por mês, as encenações eram abertas para o público em geral. Nesta versão do projeto os espetáculos foram apresentados nos teatros dos CEUs (Centros Educacionais Unificados), recém-inaugurados na ocasião. Foram 21 CEUs construídos pela prefeitura na periferia da cidade, e em cada unidade uma sala de teatro muito bem aparelhada, melhor equipada do que a grande maioria dos teatros de São Paulo. De maneira que apresentar espetáculos teatrais em condições tais - especialmente para uma parcela da população que, em grande parte, nunca havia entrado em uma sala de espetáculo, ou mesmo visto uma encenação teatral em qualquer espaço alternativo -, constituía-se em um desafio bastante estimulante.

O conceito de mediação teatral aqui trabalhado dá conta de qualquer ação que ocupe o que por alguns autores é chamado de terceiro espaço, aquele existente entre a produção e a recepção (Deldime, 1998). Podemos compreender a mediação teatral, no âmbito de projetos que visem a formação de público, como qualquer iniciativa que viabilize o acesso dos espectadores ao teatro, tanto o acesso físico, quanto o acesso lingüístico. $\mathrm{O}$ acesso físico constitui-se na viabilização da ida do público ao teatro. Ou vice-versa, da ida do teatro até o público, ou seja, na difusão de espetáculos por regiões social e economicamente desfavorecidas. Assim, podemos considerar facilitação do acesso físico iniciativas como: promoção e barateamento dos ingressos; ampla circulação das produções culturais pelos veículos de comunicação; campanhas publicitárias; a difusão das produções por regiões geográfica e socialmente afastadas; disponibilização adequada de transportes; construção de centros culturais na periferia das cidades; segurança pública, garantindo o ir e vir dos espectadores; entre tantos outros.

O acesso lingüístico, como o próprio termo sugere, opera nos terrenos da linguagem. E trata não apenas da promoção, do estímulo, mas especialmente da constituição do percurso relacional do espectador com a cena teatral, da conquista de sua autonomia crítica e criativa. Autonomia não apenas na concepção desta relação, na definição de um percurso próprio de aproximação com os elementos artísticos colocados em jogo e com os variados aspectos sensíveis e reflexivos suscitados pela cena, mas também na constituição de critérios de interpretação. A organização deste potencial de sentidos que surge na experiência artística, a elaboração de significações que constituem o ato pessoal e intransferível do espectador, como sabemos, não se limitam a um talento natural, mas precisam 
ser antes de tudo compreendidos como conquistas culturais. Conquistas nem um tanto imediatas ou evidentes, mas que, ao contrário, solicitam esforço para se efetivar. O que não quer dizer que o prazer esteja fora deste percurso. Com certeza não, mas o próprio prazer precisa ser também tomado como objeto de análise. De que prazer estamos falando afinal?

A distinção entre acesso físico e lingüístico pode facilitar a compreensão da diferença entre pensar a formação de público e a formação de espectadores. Podemos afirmar, neste sentido, que um projeto que cuide somente (o que não é pouco) da viabilização do acesso físico dos espectadores ao teatro, pode ser considerado como um projeto de formação de público teatral, considerando este em uma visada generalizante, almejando, assim, a ampliação dos freqüentadores em potencial, criando condições para o estabelecimento, em determinada parcela da população, do hábito de ir ao teatro. Por sua vez, um projeto de formação de espectadores visa não apenas a facilitação do acesso físico, mas também, e principalmente, a do acesso lingüístico, pois quer trabalhar com as individualidades, com as subjetividades, com as conquistas efetivadas por cada espectador no processo em curso.

O Projeto Formação de Público, em seu último ano de realização, se pretendia estabelecer como um projeto de formação de espectadores.

Esta noção de formação de espectadores tem em Bertolt Brecht uma figura chave. O encenador alemão compreendia esta apreensão do fazer teatral pelos espectadores como democratização dos meios de produção, possibilitando efetivar o ato do espectador como um ato artístico, autoral, produtivo. Os procedimentos de apropriação da linguagem eram por Brecht denominados como a pequena pedagogia do teatro, e podem ser observados tanto em suas investigações acerca do teatro de espetáculo - e alguns dos procedimentos adotados em seu teatro épico (Rosenfeld, 1985) podem ser destacados neste âmbito, especialmente aqueles que visavam o descortinamento do aparato teatral -, quanto nas experimentações por ele efetivadas no âmbito da peça didática (Koudela, 1991), que estavam menos preocupadas com a montagem de espetáculos, mas calcadas na própria investigação cênica dos atuantes.

A minha intenção aqui (e assim também se dava lá, no percurso do projeto) é tratar justamente dos procedimentos artísticos e pedagógicos de mediação, adotados para favorecer o encontro do espectador com a cena teatral. Contudo, quando o projeto entrou em ação em 2004, o que se viu foi a grande dificuldade que enfrentávamos ante a hercúlea tarefa de organizar aquela complicada logística das tantas escolas, grupos teatrais, monitores, agentes 
culturais dos CEUs, empresas de transportes, e demais parceiros envolvidos nesta operação. Parecia que fazer funcionar em sintonia os tantos envolvidos no projeto tomava conta de tudo. Aquilo que parece simples, quando se pensa em refinados procedimentos de mediação, tornava-se justamente o principal impedimento, e antes de superar esta etapa nada poderia acontecer de fato. Desta maneira, os primeiros desafios eram responder a questões como: em uma cidade de trânsito complicado como São Paulo, de que maneira cuidar para que os ônibus não chegassem atrasados?; quando uma das três escolas que recebíamos por sessão atrasava, o melhor seria começar ou esperar?; interrompíamos a cena para a escola atrasada entrar, ou tentávamos fazer com que cento e vinte pessoas entrassem em silêncio na sala? $\mathrm{O}$ que atrapalharia menos o evento?; no andar de cima ao da sala de teatro foi construída, em cada uma das unidades dos CEUs, uma quadra poliesportiva, e o som vazava embaixo (imaginem um jogo de basquete com o barulho da bola percorrendo o teto do teatro), como conseguir articular a necessária interrupção desta importante atividade de lazer oferecida aos alunos e moradores daquela região?; os seguranças da empresa contratada para zelar pelo espaço, posicionados no saguão do teatro, não acostumados com a sutileza do acontecimento artísticoteatral, trocavam informações por seus radiotransmissores em altos brados, e como convencê-los de que, ao invés de ajudar, eles estavam atrapalhando o evento?; o que fazer com os quatrocentos espectadores em um dia em que havia um imprevisto, como quando a longa escada de regulagem dos refletores do palco fora roubada e o grupo teatral não tinha como preparar a luz para o seu espetáculo?; o que fazer com o espectador que chegava bêbado ou armado ao teatro?; como estabelecer uma parceria fina com as escolas, de maneira que os monitores pudessem ser recebidos de forma respeitosa e com condições adequadas para a proposição das oficinas de desmontagem, oferecidas aos alunos antes e depois de cada espetáculo?

Como vimos, ainda não estamos falando mais especificamente dos procedimentos pedagógicos adotados, e sim de questões que poderíamos qualificar como operacionais. Porém, todas de suma importância para a realização da experiência artística.

Há ainda uma questão crucial para a efetivação de um projeto assim desenhado, que está relacionada com a intimidade que o grupo teatral participante tem ou não com este público, tão distinto daquele que freqüenta as salas de espetáculo nas regiões centrais da cidade. Estávamos percorrendo um território que não necessariamente todos os grupos teatrais conheciam. Um território geográfico, um território social, e mesmo um território constituído de maneira característica na dimensão do imaginário. 
E o estranhamento se apresentava na própria expectativa que a platéia trazia para o evento, percebida nas reações, nas conversas por vezes ruidosas, nos eventuais apupos, gritos, nas manifestações inesperadas. Alguns dos grupos teatrais demonstravam saber se situar neste território - especialmente aqueles que tinham, de uma maneira ou outra, a sua investigação artística embrenhada neste universo -, outros não. E aqui não se faz, necessariamente, um juízo de valor das produções, mas aponta-se para a necessária afinidade dos artistas com um projeto como este.

Isto permite que nos debrucemos sobre a conduta da platéia durante o evento. Como possibilitar que os espectadores percebam a hora de falar e a de silenciar? O silêncio pode ser também considerado como uma conquista, nem imediata, nem evidente. E que, portanto, não pode ser imposta. A imposição do silêncio, em geral, se torna muito pouco produtiva para as ambições de um projeto de formação de espectadores. Trata-se de uma questão que definitivamente não se resolve chamando a segurança e colocando para fora quem estiver se manifestando durante a cena. Pouco adianta também que os professores repreendam fortemente seus alunos, ou que os artistas interrompam a apresentação para pregar lições de boa conduta ao público presente. Ressaltese especialmente que a atitude concentrada destes espectadores na sala - e isto estava claro para nós - não se relaciona somente com a atuação dos artistas, mas com a importante ação desempenhada pelos monitores (ou mesmo pelos professores, a depender de quem organize os procedimentos de mediação), na preparação e sensibilização para o encontro. Podia-se notar que uma monitoria tinha sido bem feita na própria realização do espetáculo.

Outro aspecto importante que se podia observar era que os espectadores que tinham participado das versões anteriores do projeto, diferente dos que o integravam pela primeira vez, se mostravam mais afeitos ao encontro, passeavam mais à vontade pela leitura das cenas e tinham descoberto o prazer do silêncio, quando este se mostrava necessário.

O Formação de Público desempenhava duas ações educacionais simultâneas. Uma com a perspectiva de médio prazo, que visava a formação continuada em teatro dos professores das escolas participantes, e que tinha o intuito de que os próprios educadores assumissem futuramente a mediação pedagógica dos espetáculos. Outra com a perspectiva de atuação imediata, e que estava voltada para o próprio ato de leitura dos espectadores, que envolvia oficinas de preparação e de prolongamento para cada um dos três espetáculos que cada escola assistia durante o ano, além dos debates com os artistas no final de cada apresentação. 


\section{O curso para os professores}

O curso oferecido aos professores das escolas tinha como objetivo prepará-los para que, aprimorando seu conhecimento sobre teatro, pudessem mediar o encontro de seus alunos com esta arte. As oficinas de formação continuada estariam centradas, a partir da prática de jogos de improvisação teatral, no estudo dos variados elementos de significação presentes em uma encenação, motivando os participantes a investigarem, debaterem e apreenderem as possibilidades lingüísticas da arte teatral. De maneira que o processo fosse norteado pela experiência prática e reflexiva, estimulando os professores a experimentarem e analisarem as diversas possibilidades de comunicação que o teatro oferece, motivando-os a assumirem-se enquanto espectadores plenos e formadores capacitados. A prática teatral proposta nas oficinas do curso e na freqüentação aos espetáculos, contudo, almejava especialmente criar nos educadores o gosto por teatro, reconhecendo-o como espaço efetivo e prazeroso de produção de conhecimentos.

\section{O debate com os artistas}

Após a apresentação dos espetáculos, integrantes do grupo teatral colocavam-se no palco para conversar com os espectadores, a quem era proposto que fizessem questões ou comentários sobre a encenação. Dois objetivos principais poderiam ser ressaltados pelos artistas - que aqui precisavam posicionar-se como educadores - e pelos monitores, que mediavam este encontro: a revelação dos meandros da arte teatral, e o convite a que os espectadores formulassem concepções pessoais da cena.

Assim, nesse diálogo com o público, os artistas poderiam, destacando o primeiro dos objetivos citados, trazer informações relevantes acerca do processo e dos procedimentos adotados para a estruturação do espetáculo, possibilitando aos participantes o acesso a um conhecimento específico acerca do fazer artístico-teatral: quanto tempo leva para se ensaiar uma peça?; como se forma um artista teatral?; um ator faz cursos? Que cursos?; qual a diferença de um ator de televisão para um ator de teatro?; quantos artistas participam de uma montagem teatral?; além dos atores, que outras funções existem na construção da cena?; como e quando se monta o cenário? E assim por diante, tornando os participantes do projeto mais íntimos do processo de formação do artista e de criação do espetáculo.

O outro objetivo a ser enfocado no debate seria o de estimular os participantes do projeto a produzirem interpretações pessoais acerca dos acontecimentos cênicos. Freqüentemente, os espectadores pediam que os artistas lhes explicassem a opção por um ou outro signo cênico: por que 
vocês usaram tal elemento?; o que vocês quiseram dizer com aquilo?; qual a mensagem que vocês quiseram passar? Sugeria-se aos monitores e artistas que, nesse caso, devolvessem a pergunta, convidando os espectadores a elaborarem respostas próprias às provocações semióticas feitas pelos artistas na encenação. Mesmo que os participantes não formulassem as suas interpretações para a cena no momento do debate, poderiam levar a questão para casa, ou para debater com seus companheiros após a peça, ou com os professores na escola, ou mesmo nas oficinas de prolongamento propostas pelos monitores alguns dias depois. Além do que, os integrantes do projeto, tanto alunos quanto professores das escolas, poderiam levar consigo a certeza de que cabe a eles e a mais ninguém a tarefa de efetivar uma compreensão da experiência teatral, ainda que esta possa se enriquecer muito na conversa com outros. De maneira que os participantes estivessem seguros que a palavra de cada um e a sua formulação crítica e criativa não só estaria "autorizada”, mas seria fomentada durante todo o processo. E conquistassem a noção de que, por mais relevante que seja, a resposta do outro não lhes serve completamente nesse caso, pois o ato do espectador é necessariamente autoral, e exige uma produção pessoal.

\section{As oficinas de desmontagem}

Antes e depois da freqüentação aos espetáculos, os monitores iam até as escolas para realizar oficinas teatrais com os espectadores, tendo em vista tanto a sensibilização prévia para o evento, quanto o estímulo para a efetivação de uma leitura acurada da obra assistida.

Durante o processo nas oficinas, os mediadores propunham atividades específicas, voltadas para a exploração de determinado espetáculo, que, na ocasião, seria assistido pelo grupo. Optamos por compreender essas abordagens como ensaios de desmontagem dos espetáculos, em que algumas linhas de investigação seriam selecionadas para serem especialmente trabalhadas. A perspectiva da desmontagem está apoiada na idéia de se efetivar uma arte do espectador, tratando este como um artista em processo, propondo-lhe jogos de improvisação semelhantes aos desenvolvidos pelo grupo teatral durante a montagem. O que pressupõe a implementação de procedimentos que tornem os participantes aptos para interpretar (compreender artisticamente), tal como os artistas implementam procedimentos para interpretar (conceber artisticamente).

Esses ensaios de desmontagem eram desenvolvidos antes e depois dos espetáculos. Nos ensaios de preparação podiam ser selecionados e enfocados um ou mais aspectos lingüísticos que tivessem especial relevância em determinada montagem (a narrativa, os objetos cênicos, as canções, o gestual dos atores, 


\section{Urdimento}

${ }^{2}$ Estamos aqui compreendendo a relação do autor com 0 espectador como um jogo de linguagem, em que o primeiro age, desferindo alguns lances, e 0 segundo reage, formulando contra-lances. a iluminação etc.), visando uma aproximação prévia com o universo cênico constituinte daquela encenação. Os ensaios preparatórios tinham o intuito de oferecer vetores de análise para guiar os espectadores em sua leitura da cena - o que não significa fornecer uma análise previamente construída -, e sensibilizar a percepção dos participantes para a riqueza das resoluções cênicas levadas à cena. Ou para permitir que os espectadores, que experimentaram soluções próprias ao se depararem com aqueles elementos de linguagem nas oficinas, pudessem chegar a conclusão de que soluções cênicas diferentes (ou mesmo mais pertinentes) seriam possíveis naquele espetáculo.

Os ensaios de prolongamento, por sua vez, tinham o intuito de provocar uma interpretação pessoal dos diversos aspectos observados no espetáculo assistido pelo grupo, e estruturavam-se por procedimentos que convidassem os espectadores a criar cenas de elaboração compreensiva. Ou seja, prolongamentos criativos que buscavam dar conta das questões propostas pela encenação. Os espectadores eram convidados a conceber breves atos artísticos, que não se estruturavam enquanto continuidade do espetáculo mas enquanto exercícios interpretativos da cena em questão.

O importante, podemos concluir, não é somente o que a cena quer dizer, mas o que cada observador pode elaborar artisticamente a partir daquilo que a cena diz. Portanto, a função do mediador teatral, em oficina, seria a de estimular o participante a manifestar-se criativamente sobre a cena, efetivando a (co) autoria que lhe cabe, elaborando compreensões que vão sendo construídas para além da mera análise fria e racional do que viu. O que importa são os contra-lances ${ }^{2}$ criados pelo espectador, que indicam formulações compreensivas que concretizam o que se espera dele: a efetivação de um ato produtivo, autoral.

Os exercícios de mediação, propostos antes e depois do espetáculo, poderiam tornar perceptível para o participante do projeto a perspectiva necessariamente criativa de seu papel, evidenciando a própria função artística do espectador no evento teatral.

\section{Referências Bibliográficas}

BRECHT, Bertolt. Estudos sobre Teatro. Rio de Janeiro, Nova Fronteira, 1978. DELDIME, Roger. Introduction. In: La médiation théâtrale. Actes du 5e. Congrès internacional de Sociologie du théâtre. Morlanwelz, Lansman, p. 11-12, 1998. 
Urdimento

DESGRANGES, Flávio. A Pedagogia do Espectador. São Paulo, Hucitec, 2003. Pedagogia do Teatro: provocação e dialogismo. São Paulo, Hucitec, 2006.

KOUDELA, I.D. Brecht: um jogo de aprendizagem. São Paulo, Perspectiva, 1991. ROSENFELD, Anatol. O Teatro Épico. São Paulo, Perspectiva, 1985. 